\title{
Language dominance in bilingual first language acquisition compared to $L 2$ learners
}

\author{
Jessica Schillaci, Esli Struys \\ TALK, Vrije Universiteit Brussel, Belgium \\ https://doi.org/10.36505/ExLing-2012/05/0026/000232
}

\begin{abstract}
This fMRI study aims to compare simultaneous- and sequential Dutch-French bilinguals with respect to their dominant language. Although simultaneous bilinguals have acquired two languages from birth, it is assumed that one of both is more dominant. Three language tasks (a verbal fluency task, a grammatical judgement task and a semantic categorization task) are utilized to indicate the differences between both groups, as well as within each group (i.e. Dutch versus French). Significant differences in favor of the dominant language hypothesis were found for Dutch versus French in simultaneous bilinguals for GJT-Dutch ( $\mathrm{p}=$ $0.042)$, SCT-accuracy $(p=0.012)$ and reaction times $(p=0.004)$.
\end{abstract}

Key words : neurolinguistics, bilingualism, bilingual first language acuquisition (BFLA), language dominance

\section{Introduction}

The most common conception of a bilingual is a person "who knows two languages fluently" (Romaine, 1995:22). The obvious distinction between a simultaneous and a sequential bilingual then, would be that the first acquired two first languages at the same time (Romaine, 1995; also De Houwer, 1990; 2009). Whereas the latter acquired first one mother tongue and later one or more other languages. Still, several types and subdivisions of bilinguals have been described by numerous authors (Romaine, 1995 for an overview). The difference however is not that clear-cut.

Simultaneous bilinguals are considered to have two mother tongues, learned simultaneously and early in life (Genesee \& Nicoladis, 2006), before the age of three (McLaughlin, 1984)). Or, more strictly, from birth (e.g. Bloch et al., 2008; De Houwer, 1990; 2009; Duñabeitia et al., 2010). Notwithstanding, it is expected that simultaneous bilinguals can express themselves (slightly) better and more easily in one of both languages. Put differently, one of them is always more dominant than the other one (see Duñabeita et al., 2010). Also, it is expected that the sequential bilinguals score better on tests in their L1 (e.g. Costa \& Santesteban, 2004; Liu et al., 2009). Contrasting results were found by Hernandez (2009). The early Spanish-English bilinguals in his study were less proficient in their L1 than in their L2.

ExLing 2012: Proceedings of 5th Tutorial and Research Workshop on Experimental Linguistics, 27-29 August 2012, Athens, Greece 


\title{
Method
}

\author{
Subjects \\ The participants are students between eighteen and twenty-five years old, \\ right-handed and have normal to corrected vision. 28 subjects (15 \\ simultaneous and 13 sequential) were selected on the basis of a \\ questionnaire.
}

\section{Procedure}

Three language tests were used in both groups, in- as well as outside an MRI- scanner : a semantic categorization task, a verbal fluency task and a grammatical judgment test. Subjects lie in the scanner during the SCT. Instructions for the SCT were given in English. The instructions for the VFT and the GJT were pre-recorded and switched between French and Dutch. The sequence of the tasks was counterbalanced.

\section{Semantic categorization task or SCT}

The SCT consists of three distinct variables : animal/non-animal. Dutch/French and switch/non-switch. Subjects are given two controllers, one in each hand. 156 trials are projected on a screen. The order of the stimuli is randomized per participant (category [animal/non-animal] $x$ language [Dutch or French] $x$ [switch or non-switch]). The stimulus duration of $2200 \mathrm{~ms}$ is fixed for all participants.

\section{Verbal fluency task}

The verbal fluency task examines the participants ability to name as many words beginning with the letter $x$ in one minute. Subjects were asked to repeat this task three times, with three various letters (i.e. L, M, T) and in three diverse language-conditions (i.e. only Dutch, only French, switching between Dutch and French). The order of the letters as well as the languageconditions changed per subject.

\section{Grammatical judgment task}

The third part of Paradis' bilingual aphasia test from 1987, as adapted by Coppens was used. In both languages eight sentences, some correct and some incorrect, are read out loud (pre-recorded) to the subject. After every sentence the bilingual has got eight seconds to decide whether the sentence is correct or not (i.e. judgement). And, to correct the mistake in the sentence (i.e. correction). Both the subject's judgement as well as it's correction can be right, wrong or none.

\section{Data processing}

The behavioral data of the VFT, the GTJ and the SCT (reaction times and accuracy) were analyzed in SPSS. One sample, independent samples and paired samples t-test were computed for significance. The Levene's test was conducted to search for equality of variances. Finally, the Pearson 
Language dominance in bilingual first language acquisition $\quad 107$

correlation was conducted. The fMRI-results of the SCT (activations) were processed in Matlab-SPM. For the fMRI-data there are four missing values, bringing the total of subjects to 12 per group.

\section{Results}

Simultaneous bilinguals with Dutch as L1 score better in Dutch as well as in French as compared to the sequential bilinguals. For VFT-Dutch and GJTDutch results do not show significant differences $(\mathrm{t}(24)=1.37, \mathrm{p}=0.183$; $\mathrm{t}(24)=0.49, \mathrm{p}=0.632)$. For French the results are highly significant $(\mathrm{t}(24)=5.07, \mathrm{p}=0.000$ for VFT and $\mathrm{t}(24)=4.97, \mathrm{p}=0.000$ for GJT). Simultaneous bilinguals score better on VFT-switching (mean $=9.54(\mathrm{SD}=$ $2.82)$ versus mean $=7.77(\mathrm{SD}=1.79))$. The difference is not significant $(\mathrm{t}(24)=1.91, \mathrm{p}=0.068)$. Simultaneous learners also score better for SCT reaction times in Dutch $($ mean $=718.71(\mathrm{SD}=94.24$ versus $754.14(\mathrm{SD}=$ $179.14)$ ), reaction times in French (mean $=794.90(\mathrm{SD}=90.48)$ versus $953.34(\mathrm{SD}=170.70))$ and on accuracy in French $($ mean $=89.74(\mathrm{SD}=$ 5.86) versus $71.47(\mathrm{SD}=6.21))$. The differences in reaction times $(\mathrm{t}(20)=-$ 2.64, $\mathrm{p}=0.016)$ and accuracy $(\mathrm{t}(20)=7.04, \mathrm{p}=0.000)$ for French are significant. Sequential bilinguals score higher on accuracy $($ mean $=97.22$ $(\mathrm{SD}=1.43)$ versus $96.03(\mathrm{SD}=2.86)$ ) in Dutch. The difference, however, is not significant $(\mathrm{t}(20)=-1.20, \mathrm{p}=0.251)$.

Within the simultaneous group results for GJT (mean $=11.00(\mathrm{SD}=1.35)$ versus $9.00(\mathrm{SD}=2.97)$ ), VFT $($ mean $=12.23(\mathrm{SD}=3.442)$ versus 10.31 $(\mathrm{SD}=2.53))$, SCT-accuracy $($ mean $=96.03(\mathrm{SD}=2.86)$ versus $89.73(\mathrm{SD}=$ $5.86))$ and reaction times (mean $=718.71(\mathrm{SD}=94.24)$ versus $(794.90(\mathrm{SD}=$ 90.48)) are higher for Dutch than French. Significant results were found for GJT $(\mathrm{t}(12)=2.28, \mathrm{p}=0.042)$, reaction times $(\mathrm{t}(9)=-3.89, \mathrm{p}=0.004)$ and accuracy $(t(9)=3.16, p=0.012)$. Sequential bilinguals score better in Dutch than French for GJT (mean = 10.61 $(\mathrm{SD}=2.51)$ versus $3.62(\mathrm{SD}=2.53)$ ), VFT (mean $=10.54(\mathrm{SD}=2.847)$ versus $5.54(\mathrm{SD}=2.259)$ ), SCT-accuracy $($ mean $=97.22(\mathrm{SD}=1.43)$ versus $71.47(\mathrm{SD}=6.21))$ and reaction times $($ mean $=754.14(\mathrm{SD}=179.14)$ versus $953.34(\mathrm{SD}=170.70))$. All results are significant $(\mathrm{t}(12)=8.26, \mathrm{p}=0.000, \mathrm{t}(12)=7.07, \mathrm{p}=0.000, \mathrm{t}(11)=14.51, \mathrm{p}=$ 0.000 and $\mathrm{t}(11)=-11.70, \mathrm{p}=0.000)$.

\section{Discussion and conclusion}

Simultaneous bilinguals score better than sequentials in Dutch and French (GJT, VFT, SCT). Better results for French were expected, since their proficiency-level is higher. Results for Dutch are remarkable since their exposure to both languages was half as much compared to exposure in the sequential group. Results of the sequential speakers for Dutch versus French show a significant advantage in favor of the group's L1. This confirms the 
hypothesis that sequential bilinguals score better in their mother tongue. Within the simultaneous group a significant difference for the GJT is observed in favor of Dutch versus French. These results may confirm the existence of a dominant language in simultaneous bilinguals. The VFTDutch scores lay slightly higher than the results for French, but not significantly. A tendency versus Dutch as the more dominant language is observed nevertheless. For the SCT, the reaction times and accuracy scores are significantly better in Dutch than in French. The better scores for Dutch imply the existence of a dominant language in simultaneous bilinguals.

In conclusion, simultaneous bilinguals have one language which is more dominant than the other one. However, this is only true for language reception tasks. Despite exposure differences, simultaneous bilinguals score as well on their L1 as L2 learners, while they perform significantly better on their second language compared to sequential bilinguals.

\section{Acknowledgements}

Thanks to Piet Van de Craen, our supervisor and Ghazal Mohades for her technical assistance. Special thanks also to Olga Kępińska, Lilith Van Biesen and Thomas Somers for their help and assistance in the study.

\section{References}

Bloch, C., Kaiser, A., Kuenzli, E., Zappatore, D., Haller, S., Franceschini, R., Luedi, G., Radue, E.W. \& Nitsch, C. 2008. The age of second language acquisition determines the variability in activation elicited by narration in three languages in Broca's and Wernicke's area. Neuropsychologia 47, 625-633.

Costa, A. \& Santesteban, M. 2004. Lexical access in bilingual speech production: Evidence from language switching in highly proficient bilinguals and L2 learners. Journal of Memory and Language 50, 491-511.

De Houwer, A. 1990. Acquisition of two languages from birth: A case study. Cambridge: Cambridge University Press.

De Houwer, A. 2009. Bilingual first language acquisition. Bristol: Multilingual Matters Textbooks.

Duñabeita, J.A., Perea, M. \& Carreiras, M. 2010. Masked translation priming effects with highly proficient simultaneous bilinguals. Experimental psychology 57, 98107.

Genesee, F., \& Nicoladis, E. 2006. Bilingual acquisition. In E. Hoff \& M. Shatz (Eds.), Handbook of Language Development, Oxford : Blackwell.

Hernandez, A.E. 2009. Language switching in the bilingual brain: What's next?, Brain \& Language 109, 133-140.

Liu, H., Hu, Z., Guo, T. \& Peng, D. 2009. Speaking words in two languages with one brain: neural overlap and dissociation, Brain Research, 1316:75-82.

McLaughlin, B. 1984. Second language acquisition in childhood: Vol. 1. Preschool children $\left(2^{\text {nd }}\right.$ ed). Hillsdale, NJ: Lawrence Erlbaum.

Romaine, S. 1995. Bilingualism, $2^{\text {nd }}$ ed. Oxford : Blackwell Publishers. 